\title{
La liste des médecins de la FMH devient encore plus utile Précisez votre profil!
}

\author{
La FMH améliore et complète sa liste des médecins. Le seul registre officiel, \\ complet et constamment mis à jour, des médecins établis en Suisse dispose à \\ partir du 31 janvier 2008 d'un deuxième masque de recherche destiné à l'en- \\ semble de la population. Désormais, la liste des médecins de la FMH est un ins- \\ trument utile non seulement pour les professionnels de la santé mais aussi \\ pour les patients.
}

Secrétariat général de la FMH, Département Administration des membres
La liste des médecins de la FMH est dotée d'une nouvelle présentation attrayante et conviviale, munie de fonctions spéciales pratiques comme la recherche géographique ou un masque de recherche pour le public. Dans ce masque, les trois anciennes catégories de recherche - titres de spécialiste, formations approfondies et attestations de formation complémentaire - sont remplacées par deux nouvelles: discipline médicale et spécialisations. En outre, la discipline médicale est complétée, là où nécessaire, par les désignations médicales du langage courant telles qu'on les trouve aussi dans l'annuaire téléphonique.

Profitez, vous aussi, de ces nouvelles améliorations: complétez votre profil en cliquant sur www.myfmh.ch où vous pourrez indiquer vos domaines d'activité médicale, votre formation, vos affiliations à des organisations professionnelles et naturellement l'adresse de votre propre site internet. La mention de vos connaissances linguistiques sera particulièrement précieuse pour vos patientes et patients.

N'hésitez pas à nous contacter pour tout renseignement complémentaire sur cet élargissement de la liste des médecins. Si vous rencontrez des difficultés pour ouvrir une session ou vous enregistrer dans $m y \mathrm{FMH}$, nous vous viendrons volontiers en aide, par le biais de notre ligne d'assistance téléphonique (031 359 12 59) ou par courriel (info-dig@fmh.ch).

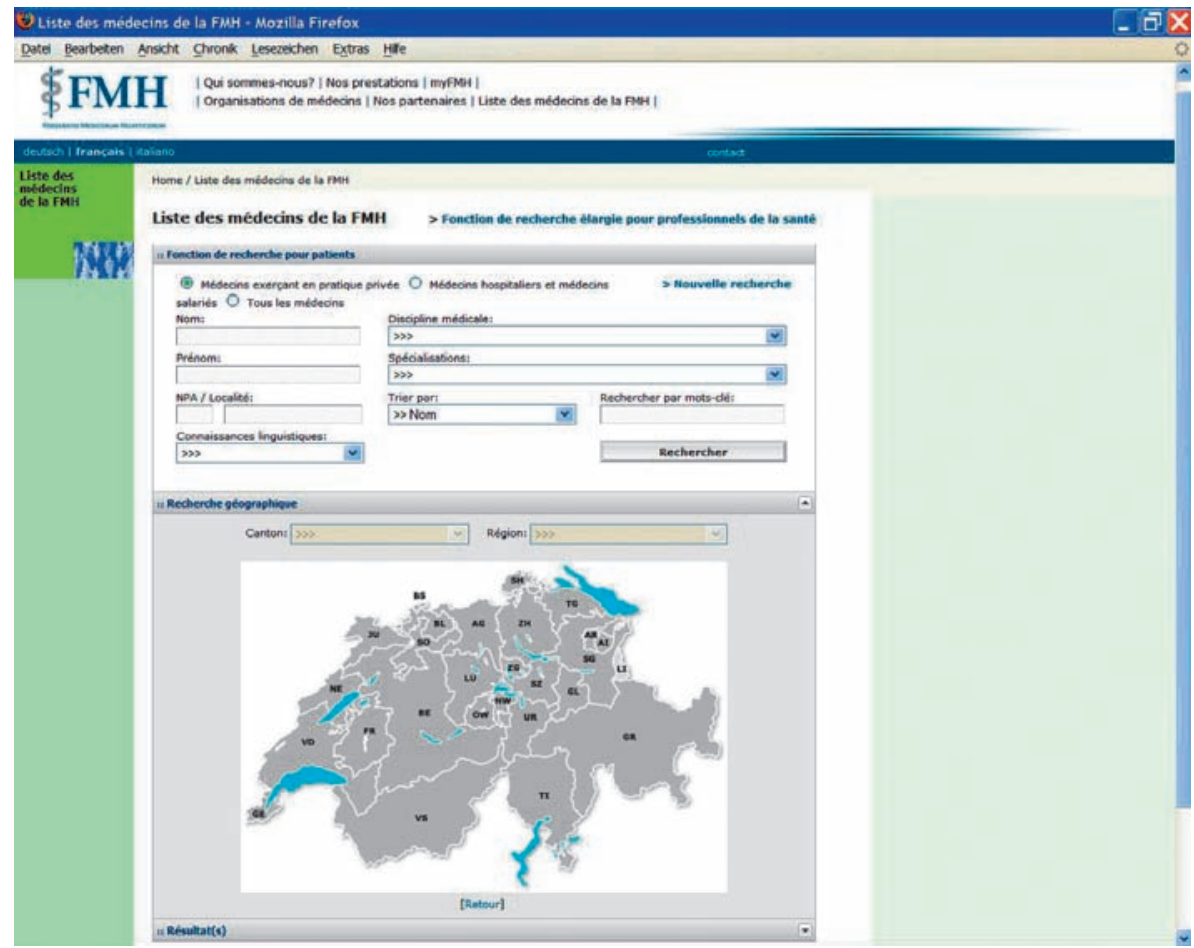

